\title{
Exposure to Tobacco Smoke and Chronic Asthma Symptoms
}

\author{
MICHAEL D. CABANA, M.D., M.P.H., ${ }^{1}$ NANCY ADAIR BIRK, M.A., ${ }^{2}$ \\ KATHRYN K. SLISH, M.A., ${ }^{3}$ ESTHER Y. YOON, M.D., ${ }^{2}$ KIRA PACE, ${ }^{2}$ \\ BIN NAN, Ph.D., ${ }^{2}$ and NOREEN M. CLARK, Ph.D. ${ }^{2,4}$
}

\begin{abstract}
The objective was to determine if tobacco exposure is associated with year-round asthma symptoms. We analyzed baseline data from a multistate survey of $\mathbf{8 9 6}$ pediatric patients with asthma participating in a randomized controlled trial. Daytime symptoms, nocturnal symptoms, and limitations in activity because of asthma tend to increase during the winter season $(p<0.05$ for all comparisons, except spring to winter daytime symptoms). One hundred forty of $896(16 \%)$ children had year-round symptoms (i.e., active asthma symptoms during every season). Using separate multivariate analyses, we found that having a parent who smokes (odds ratio [OR]: $2.22 ; 95 \%$ confidence interval $[\mathrm{CI}]: 1.35,3.64)$ or a member of the household who smokes (OR: 1.94; 95\% CI: 1.29, 2.93) was associated with a higher likelihood of year-round symptoms, controlling for region of residence, insurance status, and use of a daily controller medication. Asthma symptoms are more likely to increase in the winter season. In anticipation of these patterns, clinicians should consider initiating controller medication therapy or reinforcing asthma education prior to these time periods for those patients at risk for seasonal exacerbations. Exposure to tobacco smoke is associated with year-round asthma symptoms, highlighting the importance of health care providers identifying and counseling about smoking cessation, especially for children with year-round asthma symptoms. (Pediatr Asthma Immunol 2005; 18[4]:180-188.)
\end{abstract}

\section{INTRODUCTION}

Aeasonal variation in asthma morbidity and health care utilization, such as emergency department visits or hospitalizations, is well-documented. ${ }^{1-5}$ Various factors, including viral infections, the onset of cold weather and environmental allergens, may serve as "triggers" of asthma exacerbations contributing to asthma severity. Understanding such variation in asthma symptoms is useful in helping anticipate, manage, and control asthma symptoms.

Some patients exhibit continuous symptoms throughout the year. Indoor environmental factors, such as tobacco smoke exposure, have been posited as contributing to asthma exacerbations. The persistence of

\footnotetext{
${ }^{1}$ Division of General Pediatrics, University of California, San Francisco, San Francisco, CA 94143.

${ }^{2}$ Department of Pediatrics, University of Michigan Health System, and the Departments of ${ }^{3}$ Biostatistics and ${ }^{4} \mathrm{Health}$ Behavior \& Health Education, University of Michigan School of Public Health, Ann Arbor, MI 48109.
} 


\section{EXPOSURE TO TOBACCO SMOKE}

year-round symptoms in these patients, however, can also be affected by other factors. For instance, insurance type has been associated with decreased access to appropriate asthma care, leading to increased symptoms. ${ }^{6}$ In addition, patients who live in different parts of the country may be exposed to different climates and seasonal allergy patterns. For example, so-called opportunistic weeds (e.g., ragweed) are stimulated by higher $\mathrm{CO}_{2}$ concentrations found in warm, moist climates, leading to increased pollen production, which has been shown to demonstrate geographic and temporal variation across geographic regions. ${ }^{7,8}$ Additional influences that may have an impact on the frequency and duration of asthma symptoms include socioeconomic level, peaks in respiratory infections, and regular exposure to triggers such as pet dander, among other factors. ${ }^{9,10}$

The harmful effects of tobacco use have become increasingly prominent in medical literature as well as in the media, particularly for children and adolescents. Although multiple influences are potential contributors to the likelihood of the appearance of asthma symptoms, the purpose of this study is to determine if exposure to tobacco smoke is associated with more frequent symptoms and variations in seasonal patterns in pediatric asthma, controlling for factors such as type of insurance, regional climate, and use of daily controller medications.

\section{MATERIALS AND METHODS}

Using the baseline health status of a multistate sample of pediatric patients with asthma, we analyzed parent responses to determine seasonal patterns of asthma symptoms in children. We have published previous analyses of these data to describe environmental control actions taken by parents and comparisons of classifications of asthma severity using different measures. ${ }^{9,11}$ The University of Michigan Institutional Review Board approved the study protocol, described below.

\section{Subjects and respondents}

The 896 pediatric patients in the sample were a random sample of children with symptomatic asthma from the patient panels of pediatricians participating in a randomized controlled trial to evaluate the effect of physician asthma education.

One hundred six physicians participated in the initial randomized controlled study. The pediatricians were identified using yellow-page listings of pediatricians and membership lists from local professional societies from 10 different regions including, Corpus Christi, Texas, Bakersfield, California; Nashville, Tennessee; Jacksonville, Florida; Omaha, Nebraska; St. Paul, Minnesota; Kent County, Michigan; New Castle County, Delaware; Columbus, Ohio; and Indianapolis, Indiana. A letter and brochure were sent to pediatricians inviting them to participate in the study. They received continuing medical education credits, a certificate and $\$ 50.00$ honorarium for participating in the study.

Although the participating physicians were a convenience sample and not necessarily representative of all practicing pediatricians, we surveyed a random sample of each physician's asthma patients from lists provided by each practice. Patients and their parents were blinded to physicians' involvement in the intervention. Physicians were blind to which patients were selected for the survey.

We developed a registry of 3368 patients from the lists of patients with asthma provided by each of the participating physicians. From these 3368 patients, we randomly selected 2300 patients and were able to contact the parents of 1933. Of the 1933 patients, 856 patients were found to not meet our inclusion criteria, leaving 1077 potentially eligible patients. Criteria for inclusion in the study was as follows: a child must be between 2 and 12 years of age, have no diseases with associated pulmonary complications (such as tuberculosis, sickle cell disease, or cystic fibrosis), and have active asthma (at least one hospitalization, emergency department visit, or emergent visit [requiring the administration of epinephrine subcutaneously or a bronchodilator by aerosol or metered-dose inhaler for nondiagnostic purposes] for asthma over the past 2 years). Children younger than 2 years of age were excluded, because the diagnosis of asthma can be difficult to establish before this age. Reasons for ineligibility included no diagnosis of asthma $(n=140)$; no recent health care utilization for asthma in the last 2 years $(n=225)$; no visit with the study physician $(n=$ 114); not between 2 and 12 years of age $(n=153)$; parent works for the study physician $(n=5)$; sibling 


\section{CABANA ET AL.}

of current study patient $(n=3)$; other major disease $(n=3)$; or a combination of the above $(n=213)$. Between July 2001 and June 2002 we completed interviews with the parents of 896 of these 1077 potentially eligible patients, a response rate of $83.1 \%$.

\section{Data collection}

Trained interviewers contacted the households of randomly selected patients to administer the baseline questionnaire by telephone. Prior to telephone contact, the pediatricians sent a letter explaining the study to each of the households in their practice with potential study subjects. Parents of patients were provided with the option of contacting the physician's office to have their names removed from the list of potential subjects.

Consent was obtained from the parent or legal guardian of each pediatric patient. The interview was conducted in English. Interviewees were identified as the person who, "is usually responsible for the child's health-related care and takes him/her to the doctor."

Using an open-ended format, respondents were asked to identify the number of days in a season (specified 3-month period) the child had daytime symptoms, nighttime symptoms, and the number of days of limited daily activity because of asthma. Because recalling specifics of symptoms within a period as long as a year without some sort of reference marker is all but impossible, researchers asked parents to discuss symptoms by season. This allows for reporting of events that are associated with specific periods of the year, which improves accuracy of reporting. ${ }^{12}$

To determine exposure to tobacco smoke, we asked if the parent or guardian smoked or if anyone in the household smoked. We also collected demographic information including patient age, race, gender, asthma severity, and insurance type, respondent age and gender, household income, and number of members of the household.

\section{Definition of variables}

We defined a symptomatic season as any one season (3-month period) in which the child had greater than 27 days of daytime symptoms or limited activity (i.e., $>2$ days per week), or greater than 7 nights of nighttime symptoms (i.e., $>2$ nights per month), which was designed to mimic the National Heart, Lung, and Blood Institute (NHLBI) cutoff for persistent asthma. Seasonal asthma was defined as the patient having one symptomatic season. Year-round asthma was defined as a child having four symptomatic seasons. Fall season was defined as September through November; winter as December to February; spring as March to May; and summer as June to August.

Because we used a national sample of patients and because seasons vary across different regions of the country, ${ }^{13}$ we controlled statistically for weather and climate, which can affect asthma symptoms. ${ }^{7}$ We hypothesized that children who live in regions with low climate variability throughout the year would also be less likely to have variability in asthma symptoms throughout the year. We used the International Energy Conservation Code (IECC) climate zone system, which ranks regions based on temperature average and range, as well as precipitation. ${ }^{14} \mathrm{We}$ grouped regions into those with lower temperature variability (i.e., lower half of IECC rankings) versus those with high temperature variability (i.e., upper half of IECC rankings). Based on this definition, those children living in Corpus Christi, Jacksonville, Bakersfield/Fresno, and Nashville, were considered to live in regions of lower temperature variability.

Because younger children may be more likely to be predisposed to viral infections (e.g., bronchiolitis), which can also trigger asthma symptoms or be similar to asthma symptoms, we controlled statistically for the child's age, as reported by the parent. ${ }^{15}$

Insurance type was also self-reported and classified as private insurance, Medicaid, state programs such as the Children's Health Insurance Program (CHIP), government non-Medicaid health insurance, other, and self-pay. We hypothesized that type of insurance affects quality of and access to asthma care, and thus frequency of symptoms. ${ }^{16}$

Use of a daily controller medication was defined as the parents' report of daily use of the following types of medications: inhaled corticosteroids, theophylline, leukotriene modifiers, cromolyn sodium, and combination therapies (e.g., long acting $\beta$-agonists and daily inhaled corticosteroids). 


\section{EXPOSURE TO TOBACCO SMOKE}

\section{Analysis}

We used univariate procedures to determine the measures of central tendency for days of each symptom category, as well as univariate frequencies to determine the number of symptomatic seasons. We noted that the number of days of symptoms was skewed. As a result, to compare differences in the number of days of symptoms for each season, we used a Poisson linear regression model. Our dependent variable was the number of days of symptoms for each season. We controlled for season of the year (winter, spring, summer, or fall), with winter as the reference season, because symptoms have been documented to increase during this period. ${ }^{1,3,4}$

We used multivariate logistic regression to model the possible relationship between year-round symptoms and the following independent variables: insurance type (dichotomized into Medicaid and all other types), patient age and gender, region of residence, use of daily controller medication, and parental (or household) smoking status $(n=896)$. We were concerned about the possibility of "clustering" of patients receiving treatment by the same physician. The quality of physician care may affect the frequency of parent-reported asthma symptoms. As a result, we included a general estimating equation (GEE) in the regression analyses to allow for more robust estimates. ${ }^{17}$ Likewise, because the number of symptom days for each season represented a repeated measure for each subject, we used GEE techniques to control for clustering in all analyses. Statistical significance is defined as $p<0.05$. We used SAS 8.01 (SAS Institute, Cary, NC) for all analyses.

\section{RESULTS}

Table 1 presents the characteristics of the patients, survey respondents and households. Patients had a mean age of 7.2 years; $65 \%$ were male; and $61 \%$ reported use of a daily controller medication. There was a smoker present in $216(24 \%)$ of the households. The parent was the smoker in 112 (13\%) of the households. Regarding location, $378(42 \%)$ of the households were in a region with low temperature variability.

The most common type of insurance was described as "private" in $698(78 \%)$ households. Of the remaining households, 123 (14\%) had Medicaid; 37 (4\%) had CHIP, 15 (2\%) had government, non-Medicaid insurance, $14(2 \%)$ were self-pay, and $9(1 \%)$ were unknown or other.

Health care utilization in the previous year included an average of $0.13( \pm 0.50)$ hospitalizations; 0.77 $( \pm 1.96)$ emergency department visits and $4.4( \pm 5.0)$ office visits for asthma. Patients were under the care of their current physician for an average of $55( \pm 38)$ months.

Table 1. Patient and Respondent Characteristics $(n=896)$

$\begin{array}{lc}\text { Male } & 584(65 \%) \\ \text { Mean Age in Years (std) } & 7.2(2.9) \\ \text { Mean Months Under physician's care (std) } & 55(38) \\ \text { Respondent relationship to patient } & 836(93 \%) \\ \text { Mother } & 38(4 \%) \\ \text { Father } & 13(2 \%) \\ \text { Grandmother } & 9(1 \%) \\ \text { Other } & \\ \text { Respondent report of patient race }(n=888) & 643(72 \%) \\ \text { White/Caucasian } & 108(12 \%) \\ \text { Black/African American } & 93(10 \%) \\ \text { Hispanic } & 9(1 \%) \\ \text { Asian/Pacific Islander } & 9(1 \%) \\ \text { Native American } & 26(3 \%) \\ \text { Other } & 378(42 \%) \\ \text { Residence in a region of decreased temperature variability } & (1 \%)\end{array}$

std, standard deviation. 
CABANA ET AL.

Table 2. Mean, Median, and Mode Number of Days of Asthma Symptoms: By Symptom Type and Season

\begin{tabular}{|c|c|c|c|c|c|c|c|c|c|}
\hline & \multicolumn{3}{|c|}{ Daytime symptoms } & \multicolumn{3}{|c|}{ Nighttime symptoms } & \multicolumn{3}{|c|}{ Limitation in activity } \\
\hline & Mean (std) & Median & Mode & Mean (std) & Median & Mode & Mean (std) & Median & Mode \\
\hline Spring (March-May) & $14.2(20.8)$ & 6 & 0 & $10.6(19.7)^{*}$ & 4 & 0 & $7.7(17.6)^{*}$ & 2 & 0 \\
\hline Summer (June-August) & $7.9(15.3)^{*}$ & 3 & 0 & $6.6(15.4)^{*}$ & 1 & 0 & $5.7(16)^{*}$ & 0 & 0 \\
\hline Fall (September-November) & $13.6(19.3)^{*}$ & 6 & 0 & $10.3(17.5)^{*}$ & 4 & 0 & $7.6(16.6)^{*}$ & 2 & 0 \\
\hline Winter (December-February) & $15.3(20.3)$ & 7 & 0 & $12.0(19.5)$ & 5 & 0 & $9.0(18.1)$ & 2 & 0 \\
\hline
\end{tabular}

$* p<0.05$ compared to mean number of days during the winter season.

\section{Type and frequency of seasonal patterns}

Table 2 provides the survey items and the mean, median and mode number of symptom days for each season and symptom category. For daytime symptoms, nighttime symptoms, and limitations in activity, winter was the season with the greatest mean number of days of symptoms $(15.3 ; 12.0$ and 9.0 days; respectively). These differences were statistically significant $(p<0.05)$; except for the comparison between the mean number of daytime symptoms in winter compared to the spring season (15.3 days versus 14.2 days; $p=0.09$ ).

Table 3 displays frequency of seasons and number of symptomatic seasons. Based on our definition of seasonal symptoms, we found that $165(18 \%)$ children had seasonal asthma, with $109(12 \%)$ having two symptomatic seasons; 97 (11\%) three symptomatic seasons; 140 (16\%) four symptomatic seasons. The remaining $385(43 \%)$ children did not have any symptomatic seasons.

Of these patients with any seasonal increases in symptoms, winter (December, January, and February) was the most frequent problem season for $382(46 \%)$ children. Of the patients with only one symptomatic season, winter was also the most frequent problem season for 76 (46\%) of 165 children.

\section{Factors associated with year-round asthma symptoms}

Based on our definition of year-round asthma, we found that $16 \%$ of the patients had such symptoms. Using multivariate logistic regression analyses (Table 4, model 1), controlling for preschool age and gender, we found that parental smoking status (OR: 2.22; 95\% CI: 1.35, 3.64), receipt of Medicaid insurance (OR: 2.07; $95 \%$ CI: $1.64,4.16)$, residence in a region with decreased temperature variability (OR: 2.07 ; 95\% CI: 1.41 , 3.03 ), and receipt of a daily controller medication (OR: 3.35; 95\% CI: 2.11, 5.32) was associated with a higher likelihood of year-round symptoms. The results were similar (Table 4, model 2) when tobacco smoke exposure was represented by any member of the household smoking (OR: 1.94; 95\% CI: 1.29, 2.93).

\section{DISCUSSION}

In our sample of children with asthma, we found that asthma symptoms tend to increase during the winter season (December to February). Furthermore, 140 of 896 (16\%) children had active asthma symptoms

Table 3. Number of Seasonal Peaks

\begin{tabular}{lcc}
\hline Season & $\begin{array}{c}\text { Number of children with persistent } \\
\text { symptoms during this season }\end{array}$ & $\begin{array}{c}\text { Number of children with persistent } \\
\text { symptoms only during this season }\end{array}$ \\
\hline Spring & $319(36 \%)$ & $36(4 \%)$ \\
Summer & $119(22 \%)$ & $15(2 \%)$ \\
Fall & $334(37 \%)$ & $38(4 \%)$ \\
Winter & $382(43 \%)$ & $76(8 \%)$ \\
\hline
\end{tabular}




\section{EXPOSURE TO TOBACCO SMOKE}

Table 4. Logistic Regression Models for Increased Likelihood of Year-Round Asthma Symptoms

\begin{tabular}{lcr}
\hline Characteristic & $\begin{array}{c}\text { Model 1 } \\
\text { OR (95\% CI) }\end{array}$ & $\begin{array}{c}\text { Model 2 } \\
\text { OR (95\% CI) }\end{array}$ \\
\hline Patient age $(<5$ yrs of age versus $\geq 5$ yrs $)$ & $1.27(0.84,1.91)$ & $1.30(0.86,1.96)$ \\
Daily controller medication & $3.35(2.11,5.32)$ & $3.38(2.13,5.38)$ \\
Male gender & $0.86(0.58,1.27)$ & $0.86(0.58,1.28)$ \\
Medicaid insurance & $2.61(1.64,4.16)$ & $2.69(1.70,4.26)$ \\
Residence in region with decreased temperature variability & $2.07(1.41,3.03)$ & $2.10(1.43,3.08)$ \\
At least one parent is a smoker & $2.22(1.35,3.64)$ & - \\
At least one member of the household is a smoker & - & $1.94(1.29,2.93)$ \\
\hline
\end{tabular}

OR, odds ratio; $\mathrm{CI}$, confidence interval.

during every season (i.e., year-round asthma symptoms). Exposure to tobacco smoke, either through parental smoking or the presence of household smoking was associated with year-round symptoms. Other factors associated with an increased likelihood of year-round symptoms included use of a controller medication, Medicaid insurance, and region of residence.

Our finding that asthma symptoms are likely to worsen in the winter season is consistent with recent research. For example, the National Cooperative Inner-City Asthma Study (NCICAS) noted that inner-city children with asthma had significant worsening of wheezing symptoms during the fall and winter months with decreases in symptoms during the summer. ${ }^{3}$ The rise in symptoms is also accompanied by an increase in hospitalizations and emergency department visits due to asthma during the fall and winter months. ${ }^{1,3,4}$

In our analyses, factors associated with the likelihood of year-round asthma symptoms included region of residence. We used region of residence as a proxy for variation in temperature, as patients living in regions with less variation in temperature may be less likely to have variation in asthma symptoms throughout the year. Region may be a proxy for other factors. For example, the geographic areas we demarcated as having decreased temperature variability also have very humid climates, which may be a marker for other factors (i.e., possible year-round mold exposure).

Medicaid insurance was associated with year-round symptoms. This type of insurance may be a marker for other factors associated with access to and or quality of asthma care. ${ }^{18-20}$ For example, some researchers have suggested that asthma education, including provision of benchmarks of control by health care professionals, may not be adequate for patients with Medicaid insurance. ${ }^{21,22}$ A qualitative study noted that asthma education was often inadequate or difficult for the parents of children with Medicaid insurance to understand. ${ }^{20}$ In addition, children from families of low socioeconomic status-frequently those insured by Medicaid-may suffer from lack of regular, comprehensive health care, which can lead to poorly managed asthma. $^{23}$

Our results suggest that use of a controller medication is associated with year-round asthma symptoms. With any cross-sectional study, causality cannot be attributed in any particular direction. However, for this variable (use of a controller medication), it is likely that the year-round symptoms may lead to prescription of a controller medication, as opposed to the use of a controller medication leading to year-round asthma symptoms.

This is the first study to demonstrate an association between year-round asthma symptoms and tobacco smoke exposure. Although tobacco smoke exposure has been associated with more frequent asthma exacerbations, increased asthma symptoms, and decreased pulmonary function, we are not aware of any study that has linked tobacco smoke exposure to a specific pattern of chronic, year-round asthma symptoms. ${ }^{24,25}$ In contrast to our findings, the NCICAS study found no significant difference in wheezing patterns between those who were exposed to environmental tobacco smoke and those who were not exposed. ${ }^{3}$ The difference in findings between our study and the NCICAS study may be due to the fact that our definition of asthma symptoms included coughing or limitations in activity due to asthma, whereas their definition did not incorporate these elements. Also, unlike the NCICAS study, the population in this study was chosen from the practices of private pediatricians in medium-sized cities, versus children from inner-city clinic 


\section{CABANA ET AL.}

populations, who may not have a consistent primary care physician. In addition, instead of comparing differences in groups by average rates by each month of the year, we collapsed symptom data into seasons (3-month periods) and compared number of seasons affected.

Constant exposure to irritants may explain the association between living in a home with smokers and year-round asthma symptoms. Second-hand smoke is harmful to all individuals, but is particularly deleterious for children with asthma. Parents who smoke may have a higher level of tolerance for a child's symptoms or may be less sensitive to noticing them. For example, Crombie et al. ${ }^{26}$ found that children who live in homes with high levels of parental smoking had fewer health care contacts than children whose parents do not smoke. The authors hypothesized that there may be a lack of awareness of asthma symptoms in such situations.

\section{Limitations}

There are a number of limitations to this study. First, the data are drawn from a random sample of pediatric patients of physicians participating in a randomized controlled trial. Because physicians were not randomly selected, data obtained from the patients in the sample may not be generalizable to other populations. Second, smoking status was based on respondent self-report, which may be affected by social desirability issues. We did not confirm the smoking status of the respondent with other measures, such as urine cotinine analysis. Moreover, we did not measure the actual degree of exposure, but the only presence of smokers in the household. Third, the results of the study may vary depending on the definition of seasonal peak. For example, a more conservative definition of seasonal peak (e.g., a requirement for greater days or nights with symptoms) might lead to a slightly different interpretation of the findings, with fewer numbers of patients included in the calculations. Fourth, because the inclusion criteria required that patients have active asthma (defined as a visit to a hospital, emergency department, or physician's office for administration of epinephrine or bronchodilator), the findings may not be as generalizable to all children with varying levels of asthma. Finally, from a methodological standpoint, parents were asked to report their children's asthma symptoms over the past year; asking respondents to cluster the symptoms by season likely improved the accuracy of the reports, but multiple reports throughout the year should improve accuracy. ${ }^{12}$

\section{Implications}

There are several implications for clinicians. Similar to other studies, we found that daytime symptoms, nocturnal symptoms, and limitations in activity because of asthma are more likely to increase in the winter. In anticipation of these patterns, clinicians should consider initiating controller medications or reinforcing asthma education for those patients at risk for seasonal exacerbations prior to these time periods, perhaps as early as August or September in anticipation of the increase in symptoms occurring as the weather cools.

These results underscore the detrimental effect of tobacco smoke exposure for children with asthma. Although environmental tobacco smoke is a common trigger for asthma exacerbations in children, ${ }^{27}$ pediatricians only infrequently counsel parents who smoke to quit, and even more rarely suggest that others in the household quit. ${ }^{28}$ These results highlight the importance of identifying smokers in the household and counseling for smoking cessation, especially for those children with asthma who report year-round symptoms.

\section{ACKNOWLEDGMENTS}

Presented, in part, at the Society for Pediatric Research 2004 Annual Meeting (San Francisco, CA). Funded by The Robert Wood Johnson Foundation (Princeton, NJ).

This work represents a multidisciplinary effort including pediatric, environmental health, biostatistical and behavioral education expertise. M.D. Cabana and N.M. Clark conceived of the study and supervised all aspects of its implementation. N.A. Birk assisted with the study and completed the analyses. K.K. Slish and E. Yoon synthesized analyses. K. Pace assisted in the study and analyses of regional temperature vari- 


\section{EXPOSURE TO TOBACCO SMOKE}

ability. B. Nan supervised the statistical analyses. All authors helped to conceptualize ideas, interpret findings, and review drafts of the manuscript.

\section{REFERENCES}

1. Silverman RA, Stevenson L, Hastings HM. Age-related seasonal patterns of emergency department visits for acute asthma in an urban environment. Ann Emerg Med 2003; 42:577-586.

2. Blaisdell CJ, Weiss SR, Kimes DS, Levine ER, Myers M, Timmins S, Bollinger ME. Using seasonal variations in asthma hospitalizations in children to predict hospitalization frequency. J Asthma 2002; 39:567-575.

3. Gergen PJ, Mitchell H, Lynn H. Understanding the seasonal pattern of childhood asthma: Results from the National Cooperative Inner-City Asthma Study (NCICAS). J Pediatr 2002; 141:631-636.

4. Weiss KB. Seasonal trends in US asthma hospitalizations and mortality. JAMA 1990; 263:2323-2328.

5. Khot A, Burn R, Evans N, Lenney C, Lenney W. Seasonal variation and time trends in childhood asthma in England and Wales 1975-81. BMJ 1984; 289:235-237.

6. Cabana MD, Bruckman D, Rushton JL, Bratton SL, Green L. Receipt of asthma subspecialty care by children in a managed care organization. Amb Pediatr 2002; 2:456-461.

7. Sunyer J, Jarvis D, Pekkanen J, Chinn S, Janson C, Leynaert B, Luczynska C, Garcia-Esteban R, Burney P, Anto JM; European Community Respiratory Health Survey Study Group. Geographic variations in the effect of atopy on asthma in the European Community Respiratory Health Study. J Allergy Clin Immunol 2004; 114:1033-1039.

8. Oppenheimer JJ, Nelson HS. Seasonal variation in immediate skin test reactions. Ann Allergy Asthma Immunol 1993; 71:227-229.

9. Cabana MD, Slish KK, Lewis TC, Brown RW, Nan B, Lin X, Clark NM. Parental management of asthma triggers within a child's environment. J Allergy Clin Immunol 2004; 114:352-357.

10. Morris RD, Munasinghe RL. Geographic variability in hospital admission rates for respiratory disease among the elderly in the United States. Chest 1994; 106:1172-1181.

11. Cabana MD, Slish KK, Nan B, Clark NM. Limits of the HEDIS criteria in determining asthma severity for children. Pediatrics 2004; 114:1049-1055.

12. Schwarz N, Sudman S. Autobiographical memory and the validity of retrospective reports. New York: SpringerVerlag, 1994.

13. National Climate Data Center. Normal daily mean temperature, deg F. http://www.ncdc.noaa.gov/oa/climate/ research/monitoring.html. (Last accessed April 15, 2004).

14. International Code Council (ICC). International Energy Conservation Code, 2000 ed. Falls Church, VA: 1999.

15. Orenstein DM. Bronchiolitis. In: RE Behrman, RM Kliegman, HB Jenson, eds. Pediatrics, 16th ed. Philadelphia, PA: W.B. Saunders; 2000, pp. 1285-1287.

16. Ferris TG, Crain EF, Oken E, Wang L, Clark S, Camargo J, CA. Insurance and quality of care for children with acute asthma. Ambul Pediatr 2001; 1:267-274.

17. Liang KY, Zeger SL. Longitudinal data analysis using generalized linear models. Biometrika 1986; 73:13-22.

18. Pollock SG. Access of Medicaid recipients to outpatient care. N Engl J Med 1994; 330:1426-1430.

19. Warman KL, Jacobs AM, Silver EJ. If we prescribe it, will it come? Access to asthma equipment for Medicaidinsured children and adults in the Bronx, NY. Arch Pediatr Adolesc Med 2002; 156:673-677.

20. Monsour ME, Lanphear BP, DeWitt TG. Barriers to asthma care in urban children: Parent perspectives. Pediatrics 2000; 106:512-519.

21. Finkelstein JA, Barton MB, Donahue JG, Algatt-Bergstrom P, Markson LE, Platt R. Comparing asthma care for Medicaid and non-medicaid children in a health maintenance organization. Arch Pediatr Adolesc Med 2000; 154:563-568.

22. Apter AJ, Van Hoof TJ, Sherwin TE, Casey BA, Petrillo MK, Meehan T. Assessing the quality of asthma care provided to Medicaid patients enrolled in managed care organizations in Connecticut. Ann Allergy Asthma Immunol 2001; 86:211-218. 


\section{CABANA ET AL.}

23. Brown R, Bratton SL, Cabana MD, Kaciroti N, Clark NM. Physician asthma education program improves outcomes for children of low-income families. Chest 2004; 126:369-374.

24. Chilmonczyk BA, Salmun LM, Megathlin KN, et al. Association between exposure to environmental tobacco smoke and exacerbations of asthma in children. N Engl J Med 1993; 328:1665-1669.

25. Cook DG, Strachan DP. Summary of effects of parental smoking on respiratory health of children and implications for research. Thorax 1999; 54:357-366.

26. Crombie IK, Wright A, Irvine L, Clark RA, Slane PW. Does passive smoking increase the frequency of health service contacts in children with asthma? Thorax 2001; 56:9-12.

27. National Institutes of Health (National Heart Lung and Blood Institute). Expert panel report 2: Guidelines for the diagnosis and management of asthma. Washington, D.C.: NIH Publication No. 97-4051, 1997.

28. Cabana MD, Rand CS, Becher OJ, Rubin HR. Reasons for pediatrician nonadherence to asthma guidelines. Arch Pediatr Adolesc Med 2001; 155:1057-1062.

Address reprint requests to:

Michael D. Cabana, M.D., M.P.H. Chief, Division of General Pediatrics

University of California, San Francisco (UCSF)

3333 California Street

Laurel Heights Building \#250

San Francisco, CA 94143-0503

E-mail: mcabana@yahoo.com 
This article has been cited by:

1. Martin J Dockrell, Amanda Sandford, Sarah Ward. 2007. Smoke-free public places and their impact on public health. Expert Review of Pharmacoeconomics \& Outcomes Research 7:4, 309-313. [CrossRef]

2. Susan R. Tortolero, L. Kay Bartholomew, Marianna M. Sockrider, Stuart L. Abramson, Jennifer L. Jones, Shellie Tyrrell , Laura Freimanis , Christine M. Markham . 2007. Prevalence of Asthma Symptoms in A Screened School-Age Population of Poor Children in Houston, Texas (1997-1998)Prevalence of Asthma Symptoms in A Screened School-Age Population of Poor Children in Houston, Texas (1997-1998). Pediatric Asthma, Allergy Immunology 20:1, 11-18. [Abstract] [PDF] [PDF Plus] 